\title{
How Cognitive Biases Make Innovation Difficult in Markets for Fast Moving Consumer Goods
}

\author{
Luxin Zhang \\ ${ }^{1}$ ESCP Business school, Bachelor in Management, Haikou, Hainan, 570312, China \\ *Corresponding author.Email:luxin.zhang@edu.escpeurope.eu
}

\begin{abstract}
Biases affects our judgments and decisions everywhere, because in our daily life, no matter where you are, what kind of occupation you are doing, every decision we make is more or less interfered by cognitive biases, which even determines the outcome of things. In addition, with the development of the times, the progress of science and technology, and the change of social structure, we have experienced too many processes from rejection to acceptance, from stubbornness to change. However, it often takes time, especially in the commercial field, the timing when users accept products can better reflect this point. This article mainly aims at these phenomena, through the information, examples and data from the online sources, to explore how four kinds of cognitive biases:status quo bias, loss aversion bias, mere-exposure effect and bounded-rationality that affect the smooth progress of innovation products in the fast consumer market, and how these biases can attack the confidence of merchants, so that the originally widely favored products will eventually end in failure. At the end of the article will also discuss the heuristics that can deal with the biases.
\end{abstract}

Keywords: Status quo bias, Mere exposure effect, Loss aversion effect, bounded-rationality, Heuristic

\section{INTRODUCTION}

Innovation, which is a word that can be seen everywhere, is abundant in our daily life. From traditional telegrams to Apple that everyone has, from overseas letters to short sending messages, people's lives are endowed with more value because of innovation. However, even such innovations that are closely related to our daily lives, but sometimes it is very difficult and even meets the failure, especially in markets for consumer goods. When discussing the reasons of failure, there are many articles that say that the company does not have enough publicity, does not cater to the market, and also has marketing problems, and so forth. However, the essence of solving these problems should be to solve the problems of consumers. There is nothing wrong with innovation products, the purpose is to make life better. However, if we don't explore consumers' ideas and know their subconscious biases, and if we don't explore why they refuse the product, it may not bring the company in the right direction. This article aims to give the inspiration to the commercial company and both help companies to make a better business strategy and to make innovation more acceptable via the research method of concrete example and concrete analysis.

\section{STATUS QUO BIAS AFFECTS THE ACCEPTANCE OF INNOVATIVE PRODUCTS IN THE FAST CONSUMER MARKET}

\subsection{The Definition of STATUS QUO BIAS}

It is reckoned that the status quo is a sort of cognitive bias that can happen anytime and anywhere in our daily life, because people's emotions tend not to accept and maintain the status quo for unknown things and things that have not been experienced, because people are afraid of losing and don't want to lose what they have, which involves another bias, which the article will discuss in the next part. Therefore, there is no doubt that this kind of bias will have a series of impacts on a variety of our everyday decision-making[1].

\subsection{The Impact of STATUS QUO BIAS}

If you say how status quo bias influences consuming decisions, there will be the following examples. If you 
go to your favorite restaurant, even if it introduces several new delicious dishes, most people still have a greater tendency to choose the dishes they often order, because they are worried that the new dishes do not fit their tastes, which will make them lose both money and time.[1]Therefore, we may always be disturbed by this kind of bias in the small matter of eating, let alone making decisions in the fast consumer market. And the well-known Coca-Cola event in 1985 is also a typical example.[2] Coca-Cola tried to increase its sales and to create social topics, giving up their classic taste and packaging, and tried to attract customers' attention with a new look. However, contrary to expectations, the new Coke they were proud of had become the most famous failure of Coca-Cola Company, and has become an enduring failure case that has been analyzed by people.In that era when junk food, high-sugar and high-fat food were in vogue, Coca-Cola Company decided to make a strategic change after being hit hard by war and their market was robbed by rival company Pepsi. They carefully analyzed the market and knew that children at that time preferred sweeter things. They also did a market test before the new products were released. The testees did not reject Coca-Cola's new product, because the new product also tasted normal and was Coca-Cola, a product of a company that everyone liked. Therefore, the new cola was also on sale as scheduled. However, they didn't expect that most people didn't like the change of the new Coke at that time. They kept calling the headquarters of Coca-Cola, thinking that the change of Coca-Cola destroyed their happy memories. They thought that if the taste and packaging of Coca-Cola changed, it also meant that all their efforts and precious things ceased to exist. Even people in the south have divided this change into political conflicts, but it will not be explained here. However, the thing discussed here is why people at that time reacted so fiercely to small changes towards new Coke. Time's food critic Mimi Sheraton described the taste of new Coke as this "it is sweeter than the original formula and also has a body that could best be described as lighter. It tastes a little like classic Coca-Cola that has been diluted by melting ice."[3] In the writings of authoritative figures, Coca-Cola, which had not changed much, had been attacked by countless consumers. Even at that time, psychologists analyzed the degrees of their excessive reaction towards new changes were the same as when discussing their family deaths. It is precise because these people's status quo bias made it one of the main factors for the failure of New Coke. Because only a little change would make them worried about the end of their own era, the disappearance of their beautiful memories, and even may change their political stance to the direction of their resistance.[4] Combined with the background at that time, people desperately wanted to maintain the status quo, which led to the tragedy of New Coke. These fears of loss also lead me to discuss another bias.

\section{LOSS AVERSION BIAS PLAYS AN IMPORTANT ROLE IN THE RESON WHY CONSUMERS REFUSE INNOVATIVE PRODUCTS}

\subsection{The Definition of Loss Aversion Bias}

Without certain beliefs or special experiences, when most people consider their own choices, they tend to consider more about their own losses more than the benefits they can obtain, because "losses loom larger than gains," according to the "prospect theory".[1]At any time, for most people, the pain of losing outweighs the joy of getting.Just like the example of New Coke mentioned in the previous part, people who have just escaped from the turbulent times want to maintain the status quo and keep the existing happiness, and they are also afraid of losing what they already have, which is a good embodiment of the loss aversion bias.

\subsection{The Impact of Loss Aversion Bias}

The example was that the research by Samuelson and Zeckhauser found that It was very difficult to sell the new health insurance plan to the old workers, because for most old workers, comparing to get more benefits with taking risks, they preferred to protect their existing interests and reduce risks. Since they knew what to expect from their current plan, but they were not familiar with the new ones. Although the salesmen told them that they may get more benefits in the new ones, they were willing to choose a route to reduce the possible losses[1]. Another typical case comes from Coca-Cola Company, and another failure case of them Dasani's selling failure in the UK[2]. When talking about Dasani, many people may associate it with purity, healthy and high quality, but this is an exception in England. Because it was widely accepted by the world and blessed by the high sales volume and the corporate image of Coca-Cola Company, Coca-Cola Company was also very confident that it could easily sell well in the UK market. However, the water source of Dasani was the same as that of Thames, so it would contain the same kind of chemical substance - bromate. Even though Coca-Cola Company and their scientists have repeatedly stated that the content of bromate in Dasani water was very safe, because the content was very small, the British still refused to buy Dasani anymore because they were afraid that drinking a large amount of Dasani would make this substance unable to metabolize in their bodies, thus making them take more risks of cancers[5].All these cases tell us how much loss aversion bias will affect our daily consumption, thus this is one of the main reasons why many commercial products fail. 


\section{MERE-EXPOSURE EFFECT LIMITS MORE INNOVATIVE PRODUCTS FROM ENTERING THE MARKETS}

\subsection{The Definition of Mere-exposure Effect}

It can also be called as Familiarity Principle, especially in our shopping experiences, which describes our tendency to develop preferences for things simply because we are familiar with them[6].

\subsection{The Impact of Mere-exposure Effect}

There is a famous case about Clairol's Yogurt Shampoo[2] in 1979. Everyone knows that organic cosmetics are very popular products in recent days, especially for vegetarians, which are very creative and healthy. However, at that time, when people were outdated in cognition, it was incredible to make shampoos with yogurt. Because people were not familiar with this product and the manufacturer had not told people the benefits of washing their hair with yogurt. Therefore, consumers refused to buy the Yogurt shampoo since they were not familiar with the products, which led to the failure of Clairol's Yogurt Shampoo[7]. Another classic example can't be ignored. Burger King once launched an oil-free French fries, which was called "Satisfries"[2] considering the health of diners, but it didn't promote successfully, and it stopped selling in less than a year. The main reason was that consumers were worried that oil-free French fries would affect the taste (not at present) and made French fries taste bad, so they continued choosing traditional French fries instead of unfamiliar and uncertain products. These two cases show the impact of mere-exposure effect on our daily consumption decisions, and it is also one of the main reasons why the products that seem to be very popular nowadays could not be sold smoothly in that period.

\section{BOUNDED RATIONALITY HINDERS THE COMPANY'S PROGRESS AND LEADS TO FAILURE.}

\subsection{The Definition of Bounded-Rationality}

In 1982, Herbert Simon thought critically about the notion of human rationality and pointed out the concept of homo ecomonicus, which signifies a view of humans in the social sciences, particularly economics, as self-interested agents who seek optimal, utility-maximizing outcomes [8], and put forward the theory of bounded rationality, which implies that there are limits to our thinking capacity, available information, and time[9].

\subsection{The Influence of Bounded-rationality}

According to Calestous Juma, a professor at Harvard University' s Kennedy School of Government, "When a new invention is first propounded, in the beginning, every man objects." [10]. And his assertion is that people don' $t$ fear innovation simply because the technology is new, but because innovation often means losing a piece of their identity or lifestyle. A typical company going bankrupt because of bounded rationality must be the Kodak Company, which everyone knows. The reason Kodak fails to innovate isn' $t$ a lack of willingness to do so, but that they' re too late in recognizing opportunities (and threats) because they' re too focused on sustaining their core business, and the end result is that business ends in failure. Kodak once had a great reputation in the photography industry and even had the dominant position in the photography and film industries in 1976, accounting for $85 \%$ of the market share in the camera field and even $90 \%$ of the market share in the film industry, showing its high status[11]. Although Kodak had more than 7,000 patents, it was too conservative when faced with novel digital cameras in the 1980s[12]. As early as in 1975, Steven J. Sasson, an engineer under Kodak, invented the first electronic camera, but it was ruthlessly rejected by the director. The reason was that the management stuck to the core value system of the company too much selling analogue cameras - and failed to see digital photography as a disruptive technology. They thought that the traditional camera had a history of 100 years, people had been used to this way, and no one liked looking at their photos on a virtual screen. On the other hand, Kodak did not want to cannibalize its film roll business, so it tried to keep the new technology under the radar[11]. However, since the camera industry was gradually occupied by digital cameras, it was too late for Kodak to react. The market had already been robbed by companies like FUJIFILM [12], and no matter how hard it was, it would not help, since it had missed the best opportunity, and it would only be declared bankrupt. Therefore, it is concluded that if a company maintains the status quo too much, and be satisfied with the company's current success or interests, and do not innovate and reform at the right time, the company may eventually have a bad result caused by bounded-rationality.

\section{CONCLUSION}

In a nutshell, from all my analysis, with different classic cases, we can easily find that the essence of all cognitive biases is that for most people, people are afraid of losing or even don't want to get hurt. Under this fear, a series of biases have arisen, which affect the promotion of new products. This is one of the main reasons why innovation is in a difficult situation in the fast consumer market. But biases can also be used to eliminate biases, which depends on the wisdom of decision makers.For example, you can use anchoring heuristics[13], to market the type of yogurt " $80 \%$ Fat-Free" rather than " $20 \%$ Fat" [14], which can help to 
increase the sales of the product,since people always have a tendency to rely too heavily on the first piece of information offered[15] or you may try availability heuristics[13] to tell the purchaser that if you do not buy this product, you may lose something, because of the loss aversion bias, people always fear of losing something. Or we can also use a nudge, a form of choice architecture, which is a thought-out design of environments under which people make decisions. Nudges could help us make optimal rather than satisfactory decisions[16]. In any way or technique, the main purpose is to enable producers and consumers to establish a better trading relationship. It can not only make innovation more acceptable, but also make innovation serve people better. Because innovation does not need to be incremental but radical.

However, there are still many shortcomings in this article, for example, the biases discussed were too basic, or there are not enough solutions to better help the company's decision makers. But in the future, more efforts will be made to deeply explore the relationship between cognitive biases and innovation, and at the same time, more and better solutions are expected to be put forward.

\section{ACKNOWLEDGMENT}

During this holiday, I participated in two subject project groups, and I would like to thank Dr.Kishore Sengupta for taking me to explore more in innovation fields. I would also like to thank Dr.E.GALLO for telling me a lot about the application of behavioral economics in business. I would also like to thank my supervisor Rick Boutcher, who help me to do more critical thinking about innovation, and I also thank the teacher Yufan Huang for her guidance on the revision of my paper.Finally,I would like to thank all the publishers of the research materials quoted by me. It is absolutely impossible to have this article without you.

\section{REFERENCES}

[1]Kendra Cherry.2020. How the Status Quo Bias Affect Your Decisions. https://www.verywellmind.com/status-quo-bias-ps ychological-definition-4065385.

[2]Hitesh Bhasin, 2021. Product FailureDefinition,Reasons and 19 Examples. https://www.marketing91.com/product-failure/.

[3]Jasmine Gomez,.2019. Here's Everything You Need to Know About New Coke from "Strange Things".https://www.seventeen.com/celebrity/movi es-tv/a28749451/new-coke-stranger-things/.

[4]The huge failure of new Coke .https://ichi.pro/atarashii-ko-kusu-no-sodaina-shipp ai-78380383921009.
[5]WALESONLINE,.2004. Why Dasani failed to tap into the UK bottled water market https://www.google.co.jp/amp/s/www.walesonline. co.uk/news/local-news/dasani-failed-tap-uk-bottled -2439397.amp.

[6]The Decision Lab.Why do we prefer things that we are familiar with? https://thedecisionlab.com/biases/mere-exposure-ef fect/.

[7]Prezi,. 2015. Clairol's Yogurt Shampoo. https://prezi.com/qa3v-ygsdnmz/clairols-yogurt-sha mpoo/.

[8]The BE Hub, Bounded rationality. https://www.behavioraleconomics.com/resources/ mini-encyclopedia-of-be/bounded-rationality/.

[9]The BE Hub,. Homo economicus. https://www.behavioraleconomics.com/resources/ mini-encyclopedia-of-be/homo-economicus/.

[10]Steven Overly,. 2016. Humans once opposed coffee and refrigeration. Here' $\mathrm{s}$ why we often hate new stuff.https://www.google.co.jp/amp/s/www.washin gtonpost.com/news/innovations/wp.

[11]Seim Mol,. 2020. 6 Major companies that failed to innovate in time. https://togroundcontrol.com/blog/6-major-compani es-that-failed-to-innovate-in-time/.

[12]BRAND MINDS,. 2018. Why Did Kodak Fail and What Can You Learn from its Demise? https://brand-minds.medium.com/why-did-kodak-f ail-and-what-can-you-learn-from-its-failure-70b92 $793493 c$.

[13]Kendra Cherry,.2021. Heuristics and Cognitive Biases.https://www.verywellmind.com/what-is-a-h euristic-2795235.

[14]The Decision Lab,. Why do our decisions depend on how options are presented to us? https://thedecisionlab.com/biases/framing-effect/.

[15]PON STAFF.,2019. The Anchoring Effect and How it Can Impact Your Negotiation. https://www.google.co.jp/amp/s/www.pon.harvard. edu/daily/negotiation-skills-daily/the-drawbacks-of -goals/\%3famp.

[16]THE DECISION LAB,. Why are we satisfied by "good enough"? https://thedecisionlab.com/biases/bounded-rationali ty/. 